GRADIATION\&APPLICATIONS

ISSN 2466-4294 (online) | rad-journal.org

Vol. 2 | Issue 3 | pp. 148 - 157, 2017

doi: 10.21175/RadJ.2017.03.032

Invited review paper

\title{
PECULIARITY OF THE OPTICAL LIMITING EFFECT IN THE ORGANICS DOPED WITH FULLERENES AND RELATIVE NANOPARTICLES*
}

\author{
N.V. Kamanina $\mathbf{a}^{1,2^{*}}$ \\ ${ }^{1}$ Joint-Stock Company "Vavilov State Optical Institute”, Saint Petersburg, Russia \\ ${ }^{2}$ St. Petersburg State Electrotechnical University "LETI”, Saint Petersburg, Russia
}

\begin{abstract}
Due to important features of the organic $\pi$-conjugated nano-objects-doped systems, main properties of which can compete with the basic inorganic bulk material parameters, the study of the organics is dominant. As the effective nano-objects and the intermolecular sensitizers, the following nanoparticles, such as fullerenes, nanotubes, quantum dots, reduced graphene oxide, shungites, etc. have been considered. So many applications of the organic materials doped with nanoparticles have been proposed. Among them, the optical limiting effect occupies a unique place because this process permits, on the one side, to extend the knowledge about the photorefractive features of innovative materials and, from the other side, it is predicted to develop new devices to protect human eyes and technical equipment from high energy density of the laser beam. In the current short review paper, the optical limiting effect will be considered based on the results obtained by some scientific and engineering teams. The data will be shown at the different experimental conditions: the content of the nano-sensitizers can be changed, the range of the wave lengths can be extended, and the level of the attenuation of the laser beam can be varied. It should be mentioned that the experimental wave length can be as the following: 532, 805, 1047, 1064, 1315, 1500, $2940 \mathrm{~nm}$. The materials and optical element based on the structured organics will be shown under the application of the traditional optical limiting scheme and using the four-wave mixing technique to indicate energy losses via diffraction under the Raman-Nath diffraction conditions as one of the optical limiting mechanisms. The level of the attenuation of the laser beam will be shown for the organics based on polyimides, 2-cycloactyl-amine-5-nitropyridine, 2-(n-prolinol)-5nitropyridine, liquid crystals and other materials. Some ways to form organic photonic crystals will be discussed.
\end{abstract}

Key words: Organic electro-optical nanostructures, optical limiting effect, fullerenes, nanotubes, reduced graphene oxides, polyimide, COANP, PNP, liquid crystals, intermolecular charge transfer complex formation, IR-spectral shift, laser-induced change in the refractive index

\section{INTRODUCTION}

Since the discovery of both the fullerenes (1985) and the carbon nanotubes (1991), as well as the relative efficient nano-objects, so many research and technical groups have considered and applied the nonlinear optical properties of nanostructured materials, especially of the organics ones. It should be mentioned that this problem has been relevant until the present moment [1-10]. Among different nonlinear optical effects in the organic conjugated systems, the optical limiting (OL) process occupies a special place. It is connected with an important feature of this process, which permits to protect the human eyes, and technical devices from high laser intensity in the continuous laser mode and from high laser energy density in the pulsed mode. Due to this reason, the nanostructured organic materials have been successfully used for nonlinear optics and modulation techniques as well as in the display area. They have also been used in biomedicine to protect the eyes of surgeons from laser radiation during operations. Large types of nanoparticles have been applied as the promising sensitizers, such as fullerenes $\mathrm{C}_{60}, \mathrm{C}_{70}$ and the functionalized ones, dyes, carbon nanotubes (CNTs), quantum dots (QDs), shungites, graphene oxides, etc. The main reason to use, for example, the fullerenes is connected with their unique energy levels and high value of electron affinity energy, which can be placed in the range of 2.6-2.8 eV. This value of the electron affinity energy permits to form the intermolecular charge transfer complex (CTC) between fullerene (as intermolecular strong acceptor) and donor part of the organic matrix when the organic matrix used for the sensitization has the intramolecular interaction as well. It should be noticed that the electron affinity energy of the QDs may be higher than that for the fullerenes and can be placed in the range of 3.8-4.6 eV. The basic features of carbon nanotubes are related to their high conductivity, strong hardness of their $\mathrm{C}-\mathrm{C}$ bonds, complicated and unique mechanisms of charge carrier

\footnotetext{
* The paper was presented at the Fifth International Conference on Radiation and Applications in Various Fields of Research (RAD 2017), Budva, Montenegro, 2017.

nvkamanina@mail.ru
} 
N. V. Kamanina, Peculiarity of the optical limiting effect in the organics..., Rad. Applic., 2017, 2, 3, 148-157

moving. Really, we should take into account the approximately 7 ways for the charge carrier moving: 1 - along the nanotubes, 2 - across the nanotubes, 3 - between the nanotubes, 4 - inside the nanotubes if they are the multiwall ones, 5 and $6-$ between the organic conjugated molecules and nanotubes under the conditions of different relation of electron affinity energy of the organic molecules and nanotubes, 7 - inside the organic molecules, when the donoracceptor interaction has been revealed. The attention should be drawn on the fact that when the shungite nano-objects are used for the OL process, the own dipole moment of the shungite fragment of $2 \mathrm{D}$ should be taken into account.

Extended types of organic materials have been used as promising matrixes, such as polyimide (PI), polyvinylcarbozole (PVC), polyvinyl alcohol (PVA), polymethyl methacrylate (PMMA), 2-cyclooctylamino5-nitropyridine (COANP), poly(3-hexylthiophene), polyvinylcarbozole, 2-(n-prolinol)-5-nitropyridine (PNP), N-(4-nitrophenyl)-(L)-prolinol) (NPP), nematic liquid crystals, etc.

To interpret the optical limiting effect basically over the visible spectral range, the following mechanisms have been usually used: the reverse saturable absorption (RSA) from the molecule vibrational levels [11-15], the two-photon absorption (TPA) [11,16,17], the free carrier absorption [11], the Förster mechanism [18-20], scattering [21, 22], the thermal effect of a laser pulse $[23,24]$, the change of the light induced refractive index $[25,26]$, the intermolecular charge transfer complex formation $[27,28]$, etc. [29,30]. It should be noted that fullerene solutions, thin fullerene films, thin fullerene-doped and relative nanoparticle-doped polymer films, fullerene-doped liquid crystals, fullerene-doped sol-gel matrixes, and other organic matrixes doped with nanoobjects have been investigated under the nano-, pico- and femtosecond pulsed laser irradiation in the spectral range of 527$750 \mathrm{~nm}$ as well as in the near-infrared range. Indeed, the matrix material properties and the parameters of the applying sensitizers have been modified so that they can predict the development of new composites. It should be mentioned that, in the near-infrared spectral range, the intermolecular CTC formation plays the essential role due to the prediction of the bathochromic shift of the structured composites.

\section{BASIC EXPERIMENTAL CONDITIONS}

The basic requirements for the materials and elements based on them, which realize the effect of OL of laser radiation, can be as following:

- $\quad$ high transparency for the weak light signals;

- the ability to confine the laser light in a single pass of the beam;

- $\quad$ wide spectral range for work opportunities;

- high restriction level radiation at selected wavelengths;

- the ability to insert an OL element in a complex optical setup;

- $\quad$ simplicity in manufacture and in operation;

- etc.
The qualitative picture to explain shortly the OL effect is shown in Fig.1. One can see that the laser beam with the high laser intensity (high laser energy density) will be attenuated via transfer though the nonlinear compounds due to the large absorption cross section in the exited state. But the laser beam with the weak intensity (weak laser energy density) can be transferred without loss of the intensity. It permits to the operator to register the input irradiation with the good advantage without destroying the eyes or technical devices.

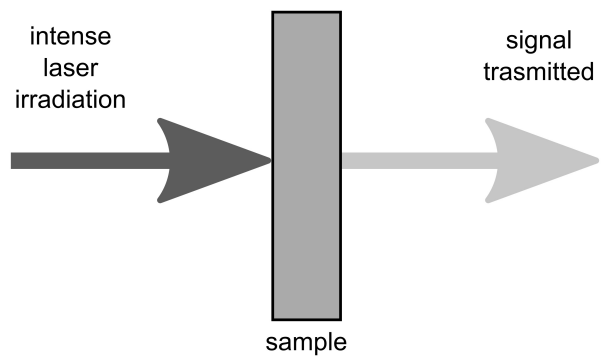

Figure 1. Qualitative model to show the OL principle

Simple OL scheme can be equivalent to the picture shown in Fig.2.

It often happens that the optical limiter cannot be able to substantially restrict the laser beam in one pass. Usually, input radiation should be decreased for a few times, and sometimes even for several orders of magnitude. In this case, a multi-stage limiter can be constructed in a way to use several mechanisms to limit laser radiation. It should be remarked that, in order to protect human eyes from any destructions, the energy density should be decreased up to the value of $10^{-6}$ $\mathrm{J} \times \mathrm{cm}^{-2}$ in the pulsed laser mode.

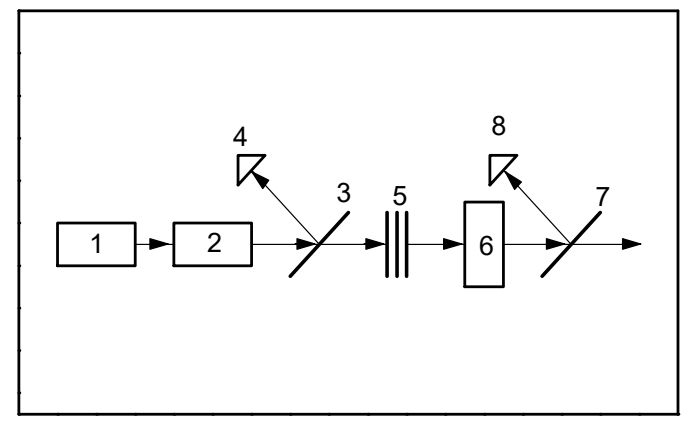

Figure 2. Variant of the OL experimental setup: 1 - laser; 2 second harmonic converter; 3,7 - beam splitters; 4, 8 photodiodes; 5 - light filters; 6 - sample studied

\section{OBTAINED RESULTS AND DISCUSSIONS}

A review of the published data allows us to conclude that the $\pi$-conjugated organic systems with fullerenes and relative nanoparticles are the most favorable subjects for investigations of modified spectral, 
N. V. Kamanina, Peculiarity of the optical limiting effect in the organics..., Rad. Applic., 2017, 2, 3, 148-157

structural, photoconductive, thermal and nonlinear optical properties. The main features of the matrix materials have been changed via fullerenes and relative nanoparticles doping. IR-shift of the spectral characteristics, charge carrier mobility changes, refractive index modifications, and order parameter improvements have been postulated in the fullereneand relative nanoparticle-doped organics.

It should be mentioned once again that the fullerenes have the unique energetic levels which permits us to make the prognosis to use them, especially at the wave length of $532 \mathrm{~nm}$. Really, according to Fig.3, the transition from ground state $S_{\text {o }}$ to the excited one $S_{x}$ is connected with the energy of $2.33 \mathrm{eV}[13,14]$.

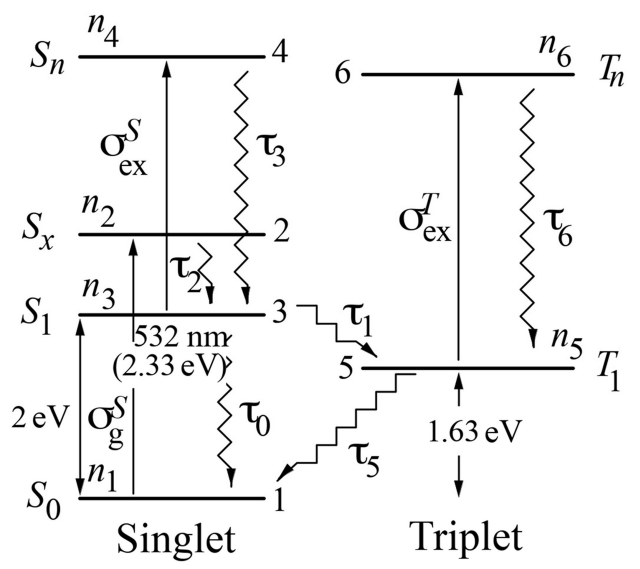

Figure 3. Energetic levels of the fullerene $\mathrm{C}_{60}$ molecules

Furthermore, the relaxation and transition times are shown in Table 1.

Table 1. C6o transition and relaxation time

\begin{tabular}{|c|c|c|}
\hline$\tau$ & Transition & Time \\
\hline$\tau_{0}$ & $S_{1} \rightarrow S_{0}$ & $650 \mathrm{ps}$ \\
$\tau_{2}$ & $S_{\mathrm{x}} \rightarrow S_{1}$ & $\sim 1 \mathrm{ps}$ \\
$\tau_{3} ; \tau_{6}$ & $S_{\mathrm{n}} \rightarrow S_{1}$ & $\sim 1 \mathrm{fs}$ \\
& $T_{\mathrm{n} \rightarrow T_{1}}$ & $\sim 1 \mathrm{fs}$ \\
$\tau_{1}$ & $S_{1} \rightarrow T_{1}$ & $1.2 \mathrm{~ns}$ \\
$\tau_{5}$ & $T_{1}$ & $40 \pm 4 \mu \mathrm{s}$ \\
\hline
\end{tabular}

According to Fig. 3 and data shown in Table 1, when the laser pulse width is longer than the time of singlettriplet intersystem crossing $(\sim 1.2 \mathrm{~ns})$, the triplet metastable state accumulates the excited molecules and the RSA mechanism is achieved through transitions $T_{n} \rightarrow T_{1}$. When the laser pulse width is shorter than the singlet-triplet intersystem crossing time, the transitions $S_{n} \rightarrow S_{1}$ operate.

Moreover, because the electron affinity of fullerenes is higher than that for the intramolecular acceptor fragment of the majority of organic molecules $[19,20,31]$, the introduction of fullerenes (as strong acceptors with the higher value of the electron affinity energy) changes the donor-acceptor interaction, reinforcing a charge transfer from a molecular donor fragment to the fullerene one. The introduction of $\mathrm{C}_{60}$ has been found to drastically enhance the photoconductivity of poly[(disilanylene)quaterphenylene\}, whereas its photoluminescence has been markedly quenched [32]. Fullerene $\mathrm{C}_{60}$ has been suggested to be an effective dopant upon light irradiation with a photon energy exceeding the band gap energy of poly[(disilanylene)quaterphenylene]. These results have been interpreted in terms of dissociation of excitons on the main chains of the compound upon encounter with $\mathrm{C}_{60}$ and electron transfer to $\mathrm{C}_{60}$. A novel $\mathrm{C}_{60}-2,6-$ bis(2,2bicyanovinyl)pyridine complex thin film has been developed [33]. This film has exhibited only two absorption broad bands at 223 and at $610 \mathrm{~nm}$, whereas there have been five absorption peaks in the spectra of parent compounds. The bathochromic shift found has been attributed to intermolecular charge transfer. Spectral, thermal and nonlinear optical properties of benzylaminofullerene and its copolymers containing methyl methacrylate or ethyl methacrylate have been investigated [34]. The absorption spectra related to the new compounds have been compared with the one of pure $\mathrm{C}_{60}$. Pure $\mathrm{C}_{60}$ has showed a main peak at $270 \mathrm{~nm}$ and a weak absorption peak at $330 \mathrm{~nm}$, while benzylaminofullerene showed a main peak at $330 \mathrm{~nm}$ and a broad absorption band at approximately 280 $\mathrm{nm}$. Under irradiation of pulsed frequency-doubled $\mathrm{Nd}$ :YAG laser with the pulse width of $7 \mathrm{~ns}$ and the wavelength of $532 \mathrm{~nm}$, the optical limiting behavior has been observed for all compounds. The $\mathrm{C}_{60}$ influence on color and glass transition temperature of copolymers has been discussed. The photoconductivity enhancement of polyvinylcarbozole has been found after fullerene ( $\mathrm{C}_{60}$ and $\mathrm{C}_{70}$ ) sensitization [35]. Photoinduced electron transfer processes has been investigated in $\mathrm{C}_{60}$-doped poly(N-vinylcarbazole) films [36]. A new broad absorption band in the 400-700 nm wavelength regions has been found. The photoconduction enhancement has been interpreted by the complex formation of $\mathrm{C}_{60}$ with a carbazole fragment of the matrix materials.

Different symmetry of $\mathrm{C}_{60}$ and $\mathrm{C}_{70}$ has caused a different effect on poly(3-hexylthiophene) [37]. It has been shown that, in contrast to $\mathrm{C}_{60}, \mathrm{C}_{70}$ is not effective as a strong dopant in poly(3-hexylthiophene). The $\mathrm{C}_{60}$ doping has decreased the energy barrier, causing electron transfer from the poly(3-hexylthiophene) molecule to fullerene due to Jann-Teller effect. The photoconductivity of $\mathrm{C}_{60}$-poly(3-hexylthiophene) has been two orders of magnitude higher than for $\mathrm{C}_{70^{-}}$ poly(3-hexylthiophene). Nonlinear transmission has been studied in $\mathrm{C}_{60}$-doped polymethyl methacrylate [38]. Coo-polymethyl methacrylate had a higher threshold for optical limiting compared with that of $\mathrm{C}_{60}$ in toluene is due to nonlinear scattering in liquids [38]. The addition of $\mathrm{C}_{60}$ increased the absorption of the material in the near-infrared region of the spectrum. Moreover, photorefractive gratings have been written and $\mathrm{C}_{60}$ predicted the increase of the diffraction efficiency [39]. The phase holograms have been recorded on $\mathrm{C}_{60}$-polymethyl methacrylate films and 
N. V. Kamanina, Peculiarity of the optical limiting effect in the organics..., Rad. Applic., 2017, 2, 3, 148-157

features of the stimulated reflection have been discussed $[14,40]$, which allowed for the fullerenedoped organic compounds to be applied not for OL but for the optical information processing as well. The bathochromic shift and the fullerene concentration dependence of absorption edge have been found in 2cyclooctylamino-5-nitropyridine structures [41,42]. The shift from the wavelength close to $420 \mathrm{~nm}$ to the wavelength close to $500 \mathrm{~nm}$ has been detected. Photoinduced electron transfer has been investigated by infrared photoexcitation spectroscopy in $\mathrm{C}_{60}$-poly(3octylthiophene) [43] A simple model for photoinduced electron transfer in conducting polymer composites with $\mathrm{C}_{60}$ has been proposed in [44].

The bathochromic shift has been found in the absorption spectra of polyimide doped with the fullerene mixture (87 wt.\% $\mathrm{C} 60$ and 13 wt.\% C70) $[45,46]$. Moreover, in these papers, the increase in photoconductivity has been observed on fullerene doping and the dependence of the optical limiting level has been obtained on the fullerene concentration. For this system, the absorption cross section for the complex with intermolecular charge transfer between the donor fragment (triphenylamine, TPA) of the polyimide molecule and fullerene as a strong intermolecular acceptor has been determined [47]. A very large absorption cross section $\sigma$ for molecules based on the D-A complex of fullerene with TPA follows from the drastic increase in absorption at the low fullerene concentration. It is in some order of magnitude more than the one for the intramolecular polyimide complexes (triphenylamine-diimide) at $\lambda$ of $\sim 530 \mathrm{~nm}$. The increase in the absorption cross section is quadratic in the ratio between dipole moments $\mu$ of optical transitions in the molecules of the fullereneTPA complex and of the intramolecular polyimide complex. Because of this, the dipole moment related to the intermolecular CTC process $\mu_{\text {inter-CTC is bigger than }}$ the dipole moment connected with the intramolecular CTC one $\mu$ intra-CTC. For the non-sensitized polyimide, it has been shown that the dipole moment is $\sim 1.52 \mathrm{D}$ but, for the fullerene-doped one, it has been close to $\sim 20 \mathrm{D}$. Moreover, the absorption peak at $1405 \mathrm{~nm}$ has been found, which has been associated with the intermolecular complex formation in fullerene-doped polyimide. This new peak has permitted to activate the OL effect in the near IR-range at the wavelength of $1315 \mathrm{~nm}$ using the iodine nanosecond laser. Future results obtained have testified that fullerene-doped polyimide structures could be applied as effective optical limiting materials for attenuating a power density of more than $2 \mathrm{~J} \times \mathrm{cm}^{-2}$ in the IR- spectral range.

In addition, the excitation transfer at the wavelength of $532 \mathrm{~nm}$ in the system based on the malachite green dye-polyimide film has been compared with the fullerene-polyimide one and the OL process has been interpreted in the context of the Förster model, because of the overlapping of the fluorescence spectrum of malachite green with the absorption spectrum of the fullerene-doped one [48]. The optical limiting effect has been explained from this point of view.

A significant enhancement of the spatial light modulator sensitivity has been found using the 151 fullerene-doped polyimide layers [49]. The investigations on nonlinear optical and mass spectroscopic characteristics of fullerene-doped polyimide have demonstrated the potentials of $\mathrm{C}_{70}$ effective doping [50,51]. A thin phase diffractive grating has been recorded by a nanosecond pulsed laser with the wavelength of $532 \mathrm{~nm}$ at the spatial frequency of $100 \mathrm{~mm}$ per $\mathrm{mm}$ in fullerene-doped polyimide and LC [52-55]. The transformation threshold of the phase grating to the amplitude one, which indicates the transition from the reversible mode to the irreversible one, has been determined. It should be noticed that the energy losses via diffraction in the reversible mode can be considered as one of the OL mechanisms as well.

It should be noticed that IR OL effect has some peculiarities connected with the significant enhancement of photoconductivity, photosensitivity, photorefractive and order parameter change, etc. In this case, there are not only fullerenes but relative nanoparticles should be used as effective dopants for many protective device applications.

Some data of the IR OL results are shown in Table 2 (Ref.56-58, 4, 59-70). The data for array inorganic materials as the matrix to develop the OL element are added for the comparison. Shift of the absorption band related to plasmon resonance with simultaneous increase in absorption coefficient; thermal change in permittivity of the components; two-photon absorption; light-induced complex formation; RSA; the influence and overlapping of the energetic levels of single wall CNTs and the organic polymers; effect of two-spectral control at the $1315 \mathrm{~nm}$; thermodynamic processes in suspensions caused by laser pulse heating with input energy density of more than $10 \mathrm{~J} \cdot \mathrm{cm}^{-2}$; nonlinear scattering; sublimation of carbon nanoparticles; multi-photon absorption; and other mechanisms have been discussed for the materials shown in Table 2. It should be remarked that, if in the visible spectral range, the dominant effect is the reverse saturated absorption but, in the near infrared range, the intermolecular charge transfer complex formation mechanism can be considered as one of the main processes.

It should be mentioned that the fullerenes has some unique features connected with their rotation ability. The investigations of the rotational behavior of the fullerenes [71, 72] have demonstrated that the reorientation time depended on temperature. The rotational reorientation of $\mathrm{C}_{60}$ in various solvents exhibited the following values of the reorientation time: in toluene, it is close to $7 \pm 1.5 \mathrm{ps}$; odichlorobenzene, $10.3 \pm 1.5 \mathrm{ps}$; o-xylene, $13 \pm 2 \mathrm{ps}$; decalin, $3.5 \pm 1.5 \mathrm{ps}$, and in chlorobenzene, $8 \pm 2 \mathrm{ps}$. Therefore, the response of fullerene changes under the light wave is very fast. This fact has been used in order to extend the explanation of the rotation mechanism of the liquid crystal dipoles under the condition of the intermolecular CTC sensitization [73]. From the obtained results, it has been shown that the switching time of the fullerene-sensitizes LC is less than the one established for the pure LC system. Thus, the reorientation in the LC could be accelerated by the fullerene introduction. A detailed study of the refractive properties of the fullerene sensitized LC has 
N. V. Kamanina, Peculiarity of the optical limiting effect in the organics..., Rad. Applic., 2017, 2, 3, 148-157

permitted to propose the model connected with the increased dipole moment via increased barrier free electron pathway and the number of the delocalized charge at fullerene molecules. This model has been shown in the paper [74] and extended using other nanoparticles as promising intermolecular sensitizers in the papers [75-77].

Table 2. Material comparative OL results for the visible and IR spectral range

\begin{tabular}{|c|c|c|c|c|}
\hline $\begin{array}{l}\text { Materials } \\
\text { treated for } \\
\text { OL }^{*}\end{array}$ & $\begin{array}{l}\text { Wave- } \\
\text { length, } \\
\text { nm }\end{array}$ & $\begin{array}{l}\text { Pulse } \\
\text { width, } \\
\text { ns }\end{array}$ & $\begin{array}{l}\text { Limiting } \\
\text { threshold } \\
\mathrm{J} \cdot \mathrm{cm}^{-2}\end{array}$ & Ref. \\
\hline $\begin{array}{l}\text { Europium and } \\
\text { thulium doped } \\
\text { oxide glasses }\end{array}$ & 5500 & $\begin{array}{l}4.5^{-} \\
45 \mathrm{ps}\end{array}$ & $\begin{array}{l}0.25-0.35 \\
\mathrm{GW} \times \mathrm{cm}^{-2}\end{array}$ & 56 \\
\hline $\begin{array}{c}\text { Silver halide } \\
\text { with NPs of } \\
\text { metallic silver }\end{array}$ & $\begin{array}{l}3800- \\
4200\end{array}$ & 250 & $\begin{array}{l}0.005^{-} \\
0.025\end{array}$ & 57 \\
\hline $\begin{array}{c}\text { 2-(n-prolinol)- } \\
5^{-} \\
\text {nitropyridine- } \\
\mathrm{C}_{60}\end{array}$ & 2940 & $500 \mu \mathrm{s}$ & $0.9-1$ & 58 \\
\hline $\begin{array}{l}\text { SWCNT-PVA } \\
\text { film }\end{array}$ & 1560 & $370 \mathrm{fs}$ & $\begin{array}{c}\sim 1 \mathrm{O}^{7} \\
\mathrm{~W} \times \mathrm{cm}^{-2}\end{array}$ & 4 \\
\hline Polyimide- $\mathrm{C}_{70}$ & 1315 & 50 & $0.08-0.1$ & 59 \\
\hline $\begin{array}{l}\text { CNTs-PVA } \\
\text { films }\end{array}$ & 1080 & 10 & 2 & 60 \\
\hline $\mathrm{Zn}-\mathrm{Pc}-\mathrm{C}_{60}$ & 1064 & $\mathrm{~ns}$ & & 61 \\
\hline $\begin{array}{l}\text { Carbon-black } \\
\text { suspensions } \\
\text { both in water } \\
\text { and in } \mathrm{CS}_{2}\end{array}$ & 1064 & 10 & $0.12-0.7$ & 62 \\
\hline $\begin{array}{c}\text { Carbon } \\
\text { nanotube } \\
\text { suspensions in } \\
\text { chloroform }\end{array}$ & 1064 & 5 & $0.15-0.35$ & 63 \\
\hline $\mathrm{C}_{60}$ solution & 1064 & $35 \mathrm{ps}$ & $\sim 3$ & 64 \\
\hline $\begin{array}{l}\text { Polyimide- } \\
\text { graphene } \\
\text { oxides }\end{array}$ & 1064 & 10 & 0.7 & 65 \\
\hline Polyimide- $\mathrm{C}_{70}$ & 1047 & 8 & $0.6-0.7$ & 66 \\
\hline $\begin{array}{l}\text { LC+COANP- } \\
\mathrm{C}_{70} \text { film }\end{array}$ & 805 & $70 \mathrm{fs}$ & $\begin{array}{c}500 \\
\mathrm{~W} \times \mathrm{cm}^{-2}\end{array}$ & 67 \\
\hline $\mathrm{C}_{60}$ solution & $\begin{array}{l}710- \\
740\end{array}$ & 10 & 2 & 68 \\
\hline $\begin{array}{c}\text { Water Soluble } \\
\text { CdSe } \\
\text { Quantum Dots }\end{array}$ & 532 & 7 & $\begin{array}{l}0.35-0.57 \\
\mathrm{GW} \times \mathrm{cm}^{-2}\end{array}$ & 69 \\
\hline $\begin{array}{c}\text { Silver } \\
\text { nanodots film }\end{array}$ & 532 & $25 \mathrm{ps}$ & $\begin{array}{c}1-1.5 \\
\mathrm{GW} \times \mathrm{cm}^{-2}\end{array}$ & 70 \\
\hline
\end{tabular}

*It should be mentioned that the initial transmission of the systems show has been placed in the range of $60-90 \%$.

It has been shown that in such sensitized organic conjugated systems the pathway of the charge transfer carrier is changed due to a fact that charge transfers from the intramolecular donor fragment of organic conjugated molecules (such as polyimide, polyaniline, pyridine, etc.) is directed not to its intramolecular acceptor fragment but to nanoobjects if the electron affinity energy of the nanoobjects is higher than that for intramolecular acceptor fragment. For example, the electron affinity energy of an intramolecular acceptor fragment of polyimide is close to $1.1-1.4 \mathrm{eV}$, the electron affinity energy of shungite structure is $\sim 2 \mathrm{eV}$, the same one for fullerenes is $\sim 2.65-2.68 \mathrm{eV}$. Thus, the intermolecular acceptor fragment is two times higher.
Analyzing some pyridine compounds, for example, 2cyclooctylamino-5-nitropyridine, it can be noticed that the optical density has been observed and additional absorption bands close to 500 and $800 \mathrm{~nm}$ come into existence. Moreover, a variation of the film color is observed from light yellow (pure COANP) to light brown $\left(\mathrm{C}_{70}-\mathrm{COANP}\right)$. This fact does not contradict the donor-acceptor complex formation between the donor fragment (an HN group) of the COANP molecule and fullerene as a strong acceptor. It should be noticed that the acceptor fragment of the COANP molecule is an $\mathrm{NO}_{2}$ group, which is bound with the donor fragment by a benzene ring. The electron affinity of an individual molecule or radical $\mathrm{NO}_{2}$ is $2.3 \mathrm{eV}$, but the electron affinity of the $\mathrm{NO}_{2}$ group bound with the benzene ring is only $0.54 \mathrm{eV}$, which more than four times less than that of fullerene. Thus, the fullerene molecule dominates the acceptor $\mathrm{NO}_{2}$ group in COANP and changes the intramolecular donor-acceptor interaction to the intermolecular one. The photoconductivity measurements and the mass spectroscopy investigations of the $\mathrm{C}_{70}$-COANP system are additional arguments in favor of the CTC formation [78]. The mass spectroscopy data point to CTC formation between fullerene and triphenylamine and between fullerene and the HN group in the C70-PI and $\mathrm{C}_{70} \mathrm{O}-$ COANP systems, respectively. The curves for the $\mathrm{C} 70$ release rate on heating the films of PI and COANP structures contained different peaks. For the 0.5 wt.\% $\mathrm{C}_{70}$-PI film, curve contains three peaks. The first one is also observed close to $400{ }^{\circ} \mathrm{C}$. The second peak is located at $560{ }^{\circ} \mathrm{C}$ and associated with the decomposition of fullerene- triphenylamine complex. It should be noted that the melting temperature of these PIs is $700-1000{ }^{\circ} \mathrm{C}$ [79], thus, the third peak at the temperature higher than $700{ }^{\circ} \mathrm{C}$ corresponds to the total decomposition of PI. For the 5 wt. $\% \mathrm{C}_{70}$-COANP film, the curve contains two peaks. The first one at 400 ${ }^{\circ} \mathrm{C}$ corresponds to the release rate of fragments with free fullerene masses. The second one is shifted to the temperature range of $520{ }^{\circ} \mathrm{C}$ and associated with the decomposition temperature of the fullerene-HN group complex. Thus, mass-spectrometry results support the CTC formation with good advantage. Moreover, for this fullerene-doped COANP structure, the increase of the dipole moment via intermolecular CTC process has been shown in the paper [80] based on the quantumchemical simulations. The characteristics of the electronic states of $\mathrm{C}_{60}+\mathrm{COANP}$ and $\mathrm{C}_{70}+\mathrm{COANP}$ have been calculated and the increase of the dipole moment in the sensitized COANP has been shown.

It should be repeated that the spectral range of efficient RSA for $\mathrm{C}_{60}$ molecules extends from 400 to $700 \mathrm{~nm}$ [81]. At $\lambda<400 \mathrm{~nm}$, the condition $\sigma^{\mathrm{S}, \mathrm{T}} \mathrm{ex}>\sigma_{\mathrm{g}}^{\mathrm{S}}$, necessary for efficient RSA, is reversed, while at $\lambda>700 \mathrm{~nm}$, the cross section $\sigma^{\mathrm{S}} \mathrm{g}$ becomes too small. For fullerenes of higher orders, $\mathrm{C}_{70}$ and higher $\left(\mathrm{C}_{78}, \mathrm{C}_{84}\right.$, etc.), the limiting effect due to RSA is pronounced even above $700 \mathrm{~nm}$ [82].

In the current review based on the matrix sensitized materials such as: polyimide, polyvinylcarbozole, polyvinyl alcohol, polymethyl methacrylate, 2-cyclooctylamino-5-nitropyridine, poly(3hexylthiophene), polyvinylcarbozole, 2-(n-prolinol)-5nitropyridine, N-(4-nitrophenyl)-(L)-prolinol), nematic 
liquid crystals, etc. - the extended spectral area for the OL via effective intermolecular CTC formation has been shown.

Therefore, the incorporated nanoobjects are stronger sensitizers and they dominate the acceptor fragments of intra-molecular complexes. In this case, the field gradients are formed and the enhanced additional dipole moment is observed. Moreover, the increase of local volume polarizability is found, and the increase of the charge carrier mobility is revealed. Furthermore, this model has been applied to the bioobject-doped organics, which has been presented in the papers [83-87]. It can be shown in modified version in Fig.4. Different views of nanoparticles as effective intermolecular acceptors are added in this model consideration step by step.

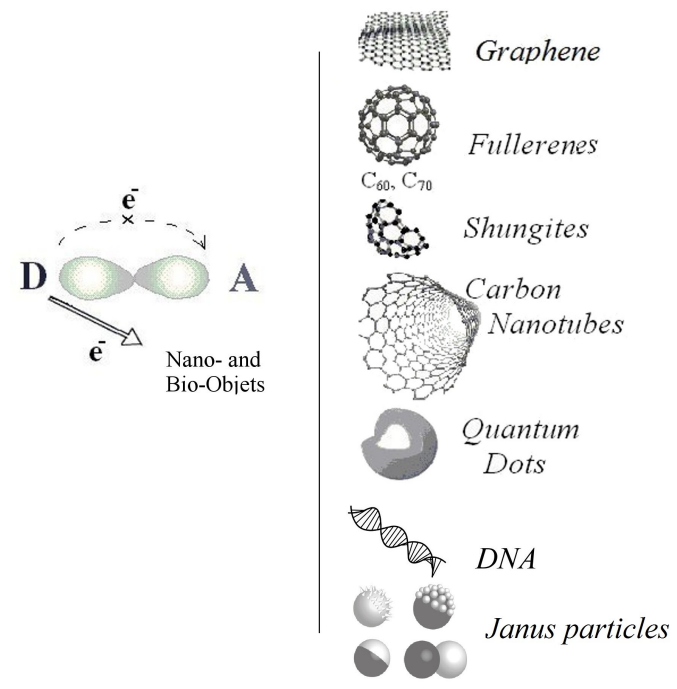

Figure 4. Qualitative model to show the creation of the intermolecular donor-acceptor interaction via electron transfer from the intramolecular donor fragment (left) to the intermolecular acceptor (right)

It should be noticed that the refractive experiments by using the four wave mixing technique testified that the $3 \mathrm{D}$ structures have been obtained in the doped organics. It is connected with the change of the laser induced refractive index and, as a result, the existence of the energy losses due to diffraction on the nanostructured compounds can be included in the explanation of the OL effect. The obtained $3 \mathrm{D}$ picture is firstly shown in papers $[77,85]$ and is now presented in the modified version in Fig.5. It should be mentioned that this modified version of the diffraction picture is connected with the large number of results obtained for the structured conjugated organics materials via fourwave mixing laser technique and repeated so many times. The laser scheme has been operated under the Raman-Nath diffraction conditions at different spatial frequencies and energy density. It should be remarked that this diffractive grating view has been obtained when the reversible mode of the laser activation has been transferred in the irreversible one in order to receive the replica of the visualization of the lasermatter interaction.

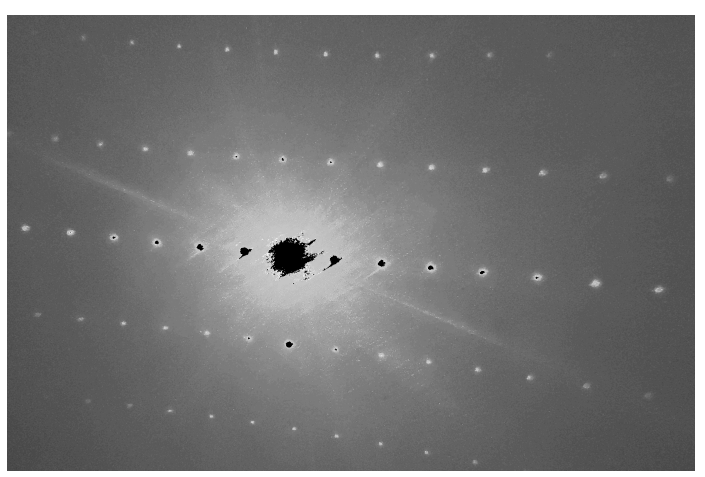

Figure 5 . General view of the diffractive gratings recorded under the Raman-Nath diffraction condition at the nanostructured conjugated organic materials

\section{Present tendency}

According to the database of the considered organic systems one can postulate that these materials can replace the inorganic bulk crystals, for example, such as $\mathrm{LiNbO}_{3}$, quartz, KDP, DKDP, etc. in order to activate the OL mechanisms in them, to write and record the amplitude-phase thin holographic gratings, etc. Taking this fact into account, it should be noticed that the use of conjugated organics is dominant in modified optoelectronic components. As a rule, these organic structures are the systems with the thickness of several microns but their refractive parameters can be compared with inorganic crystals with the thickness of 5-10 $\mathrm{mm}$. The organics elements can be incorporated in different optical complex schemes with good advantages.

It should be taken into account that, for the organic materials, it is very important to draw attention to the interface between the used substrate and thin organic conjugated films [87]. It predicts the order parameter change and the spectral IR shift variation, as well [88].

\section{CONCLUSIONS}

To summarize the data about the nonlinear features of the conjugated organics materials, especially, to establish and to realize the OL mechanism in them, one can conclude the following:

Organic systems with different sensitizers can be applied as the perspective elements for the general optoelectronics and laser complex schemes, as well.

As the promising sensitizers, the fullerenes, carbon nanotubes, graphene oxides, shungites, quantum dots, J-aggregates, Janus nanoparticles, DNA, etc. can be considered.

Reverse saturable absorption; two-photon absorption; Förster process; thermal change in permittivity of the components; light-induced complex formation; the energy losses due to diffraction on the nanostructured compounds, etc. can be included in the explanation of the OL effect.

Possibly, renewable DNA structures can be considered as good candidates to modify the photorefractive features of the organic materials with 
N. V. Kamanina, Peculiarity of the optical limiting effect in the organics..., Rad. Applic., 2017, 2, 3, 148-157

an initial donor-acceptor interaction that can predict to use the bio-sensitization process in the development of the OL elements, as well. Bio-sensitization permits to create the nontoxic renewable compounds.

Acknowledgement: The paper is a part of the research done within the RFBR Grants No. 1O-O3oo916 (2010-2012) and No.13-03-00O44 (2013-2015) as well as it supported by the FP7 Program, Marie Curie International Researchers Exchange Proposal "BIOMOLEC"(2011-2015).

\section{REFERENCES}

1. M. Hasegawa, K. Horie, "Photophysics, photochemistry and optical properties of polyimides," Prog. Polym. Sci., vol. 26, no. 2, pp. 259 - 335, Mar. 2001. DOI: $10.1016 /$ So079-6700(00)00042-3

2. B. G. Sumptera, D. W. Noida, M. D. Barnes, "Recent developments in the formation, characterization, and simulation of micron and nano-scale droplets of amorphous polymer blends and semi-crystalline polymers," Polymer, vol. 44, no. 16, pp. $4389-4403$, Jul. 2003. DOI: 10.1016/So032-3861(03)00428-2

3. D.-Y. Wang et al., "Large optical power limiting induced by three-photon absorption of two stilbazolium-like dyes," Chem. Phys. Lett., vol. 369, no. 5-6, pp. $621-$ 626, Feb. 2003. DOI: 10.1016/Sooo9-2614(03)00004-6

4. A. G. Rozhin, Y. Sakakibara, M. Tokumoto, H. Kataura, Y. Achiba, "Near-infrared nonlinear optical properties of single-wall carbon nanotubes embedded in polymer film," Thin Solid Films, vol. 464-465, pp. $368-372$, Oct. 2004.

DOI: 10.1016/j.tsf.2004.07.005

5. J. Wang, Y. Chen and W. J. Blau, "Carbon nanotubes and nanotube composites for nonlinear optical devices," J. Mater. Chem., vol. 19, no. 40, pp. 7425 7443, Aug. 2009.

DOI: $10.1039 /$ b906294g

6. D. N. Christodoulides, I. C. Khoo, G. J. Salamo, G. I. Stegeman and E. W. van Stryland, "Nonlinear refraction and absorption: mechanisms and magnitudes," Adv. Opt. Photonics, vol. 2, no. 1, pp. 60 200, 2010.

DOI: 10.1364/AOP.2.000060

7. R. Kh. Manshad and Q. M. A. Hassan, "Optical limiting properties of magenta doped PMMA under CW laser illumination," Adv. Appl. Sci. Res., vol. 3, no. 6, pp. $3696-3702,2012$. Retrieved from:

http://www.imedpub.com/articles/optical-limitingproperties-of-magenta-doped-pmma-under-cwlaserillumination.pdf

Retrieved on: Jan. 28, 2017

8. L. Wang, R. Peng, Y. Zhao, F. Wu, "Optical Limiting and Stabilization Properties of a Liquid Dye on $1064 \mathrm{~nm}$ Nanosecond Laser Pulses," Opt. Photonics J., vol. 3, pp. 34 - 37, Jun. 2013. DOI: 10.4236/opj.2013.32Boo8

9. D. Dini, M. J. F. Calvete and M. Hanack, "Nonlinear Optical Materials for the Smart Filtering of Optical Radiation," Chem. Rev., vol. 116, no. 22, pp. 13043 13233, Nov. 2016.

DOI: 10.1021/acs.chemrev.6booo33 PMid: 27933768

10. Y. Wang, M. Lv, J. Guo, Y.-W. Yang, "Carbon-based optical limiting materials," Sci. China Chem., vol. 58, no. 12 , pp. $1782-1791$, Dec. 2015. DOI: $10.1007 / \mathrm{s} 11426-015-5480-0$
11. L. W. Tutt, T. F. Boggess, "A review of optical limiting mechanisms and devices using organics, fullerenes, semiconductors and other materials," Prog. Quant. Electron., vol. 17, no. 4, pp. $299-338,1993$.

DOI: 10.1016/0079-6727(93)90004-S

12. A. Kost et al., "Optical limiting with $\mathrm{C}_{60}$ solutions," in Proc. Int. Symp. Opt. Eng. Photonics Aerospace Sensing SPIE vol. 2229, Orlando (FL), USA, 1994, pp. $78-90$.

DOI: 10.1117/12.179574

13. S. Couris, E. Koudoumas, A. A. Ruth and S. Leach, "Concentration and wavelength dependence of the effective third-order susceptibility and optical limiting of $\mathrm{C}_{60}$ in toluene solution," J. Phys. B At. Mol. Opt. Phys., vol. 28, no. 20, pp. 4537 - 4554, Oct. 1995. DOI: $10.1088 / 0953-4075 / 28 / 20 / 015$

14. V. P. Belousov et al., "Fullerenes: Structural, physicalchemical, and nonlinear optical properties," J. Opt. Technol., vol. 64, pp. 1081 - 1109, 1997.

15. F. Lin et al., "Optical limitation and bistability in fullerene," J. Appl. Phys., vol. 74, no. 3, pp. 2140 2142, Aug. 1993

DOI: $10.1063 / 1.354743$

16. J. R. Lindle, R. G. S. Pong, F. J. Bartoli, Z. H. Kafafi, "Nonlinear optical properties of the fullerenes $\mathrm{C}_{60}$ and $\mathrm{C}_{70}$ at 1.064 um," Phys. Rev. B, vol. 48, no. 13, pp. 9447 - 9451, Oct. 1993. DOI: $10.1103 /$ PhysRevB.48.9447

17. K. McEwan, R. Hollins, "Two-photon-induced excitedstate absorption in liquid crystal media," Proc. Int. Symp. Opt. Eng. Photonics Aerospace Sensing SPIE vol. 2229, Orlando (FL), USA, 1994, pp. 122 - 130.

DOI: $10.1117 / 12.179578$

18. N. V. Kamanina, "Reverse saturable absorption in fullerene-containing polyimides. Applicability of the Förster model," Opt. Commun., vol. 162, no. 4-6, pp. 228 - 232, Apr. 1999.

DOI: 10.1016/So030-4018(99)00095-4

19. N. V. Kamanina, "Study of reverse absorption saturation in fullerene-containing polyimides," Opt Spectrosc., vol. 88, no. 6, pp. 944 - 947, Jun. 2000. DOI: $10.1134 / 1.626905$

20. N. V. Kamanina, "Nonlinear optical study of fullerenedoped conjugated systems: new materials for nanophotonics applications," in NATO Science Series Series II: Mathematics, Physics and Chemistry: Organic Nanophotonics, vol. 100, F. Charra, V. M. Agranovich, F. Kajzar, Eds., Dordrecht, Netherlands: Springer, 2003, ch. 17, pp. $177-192$, 2003.

DOI: 10.1007/978-94-010-0103-8_17

21. I. M. Belousova et al., "Peculiarities of optical limiting mechanism in liquid, polymer, and solid-state fullerene-containing media," Nonlinear Optics, vol. 27. no. 1-4. pp. $219-231,2001$

22. S. R. Mishra, H. S. Rawat, M. P. Joshi, S. C. Mehendale, "The role of non-linear scattering in optical limiting in C60," J. Phys. B At. Mol. Opt. Phys., vol. 27, no. 8, pp. L157 - L163, Apr. 1994. DOI: $10.1088 / 0953-4075 / 27 / 8 / 005$

23. S. R. Mishra, H. S. Rawat, M. P. Joshi, S. C. Mehendale, K. C. Rustagi, "Optical limiting in $\mathrm{C}_{60}$ and $\mathrm{C}_{70}$ solutions," in Proc. Int. Symp. Opt. Imaging and Instrumentation SPIE vol. 2284, San Diego (CA), USA, 1994, pp. $220-229$.

DOI: $10.1117 / 12.196132$

24. G. Gu et al., "Large non-linear absorption in $\mathrm{C}_{60}$ thin films,” J. Phys. B At. Mol. Opt. Phys., vol. 26, no. 15, pp. L451 - L455, Aug. 1993. DOI: $10.1088 / 0953-4075 / 26 / 15 / 004$

25. N. D. Kumar et al., "Fabrication of GRIN-materials by photopolymerization of diffusion-controlled organicinorganic nanocomposite materials," in Proc. Symp. 
N. V. Kamanina, Peculiarity of the optical limiting effect in the organics..., Rad. Applic., 2017, 2, 3, 148-157

Better Ceramics Through Chemistry VII: Organic/Inorganic Hybrid Mater., San Francisco (CA), USA, 1996, pp. $553-558$.

26. I. C. Khoo, H. Li, Y. Liang, "Observation of orientation photorefractive effects in nematic liquid crystals," Opt. Lett., vol. 19, no. 21, pp. 1723 - 1725, Nov. 1994.

DOI: 10.1364/OL.19.001723 PMid: 19855634

27. J. R. Heflin, S. Wang, D. Marciu, C. Figura, R. Yordanov, "Optical limiting of $\mathrm{C}_{60}, \mathrm{C}_{60}$ chargetransfer complexes, and higher fullerenes from 532 to $750 \mathrm{~nm}$," in Proc. Fullerens and Photonics II SPIE vol. 2530, San Diego (CA), USA, 1995, pp. $176-187$. DOI: $10.1117 / 12.228117$

28. W. N. Sisk, D. H. Kang, M. Y. A. Raja, F. Farahi, "Photocurrent and optical limiting studies of $\mathrm{C}_{60}$ films and solutions," Int. J. Optoelectronics, vol. 11, no. 5, pp. 325 - 331, Sep. 1997

Retrieved from:

https://www.researchgate.net/publication/297405410; Retrieved on: Jan. 28, 2017

29. E. J. Nicol, "Optical properties of doped fullerenes in the superconducting state", Physica B Condens. Matter., vol. 194-196, pp. 2065 - 2066, Feb. 1994. DOI: 10.1016/0921-4526(94)91532-6

30. P. J. Hood, B. P. Edmonds, D. G. McLean, D. M. Brandelik, "Comparison of optical power limiting in carbon-black suspensions, $\mathrm{C}_{60}$ in toluene and $\mathrm{C}_{60}$ in chloronaphthalene at $694 \mathrm{~nm}$," in Proc. Int. Symp. Opt. Eng. Photonics Aerospace Sensing SPIE vol. 2229, Orlando (FL), USA, 1994, pp. 91 - 99. DOI: $10.1117 / 12.179575$

31. H.W. Kroto, J. E. Fischer and D. E. Cox, The Fullerenes, Oxford, UK: Pergamon Press Ltd., 1993.

32. K. Hosoda, K. Tada, M. Ishikawa and K. Yoshino, "Effect of $\mathrm{C}_{60}$ doping on electrical and optical properties of poly[(disilanylene) oligophenylenes]," Jpn. J. Appl. Phys., vol. 36, no. 3B, pp. L372 - L375, Mar. 1997. DOI: 10.1143/JJAP.36.L372

33. M. Ouyang et al., "Study of a novel C6o-2,6-bis(2,2bicyanovinyl)pyridine complex thin film," Appl. Phys. Lett., vol. 68, no. 17, pp. 2441 - 2443, Apr. 1996.

DOI: $10.1063 / 1.116161$

34. Z. Lu, S. H. Goh, S. Y. Lee, X. Sun and W. Ji, "Synthesis, characterization and nonlinear optical properties of copolymers ofbenzylaminofullerene with methyl methacrylate or ethyl methacrylate," Polymer, vol. 40, no. 10, pp. 2863-2867, May 1999. DOI: 10.1016/Soo32-3861(98)oo554-o

35. Y. Wang, N. Herron and J. Caspar, "Bucky ball and quantum dot doped polymers: a new class of optoelectronic materials," Mater. Sci. Eng. B, vol. 19, no. 1-2, pp. 61-66, Apr. 1993. DOI: 10.1016/0921-5107(93)90166-K

36. A. ltaya, I. Suzuki, Y. Tsuboi and H. Miyasaka, "Photoinduced electron transfer processes of $\mathrm{C}_{60}$-doped poly(N-vinylcarbazole) films as revealed by picosecond laser photolysis," J. Phys. Chem. B, vol. 101, no. 26, pp. $5118-5123$, Jun. 1997. DOI: $10.1021 /$ jp970303o

37. K. Yoshino, X. H. Yin, S. Morita and A. A. Zakhidov, "Difference in doping effects of $\mathrm{C}_{60}$ and $\mathrm{C}_{70}$ in poly(3hexyithiophene)," Jpn. J. App. Phys., vol. 32, no. 1A/B pp. L140 - L143, Jan. 1993. DOI: 10.1143/JJAP.32.L140

38. A. Kost, L. Tutt, M. B. Klein, T. K. Dougherty and W. E. Elias, "Optical limiting with $\mathrm{C}_{60}$ in polymethyl methacrylate," Opt. Lett., vol. 18, no. 5, pp. 334 - 336, Mar. 1993.

DOI: $10.1364 /$ OL.18.000334

PMid: 19802127

39. S. M. Silence, C. A. Walsh, J. C. Scott and W. E. Moerner, "C6o sensitization ofphotorefractive polymers," Appl. Phys. Lett., vol. 61, no. 25, pp. 2967 2969, Dec. 1992.

DOI: $10.1063 / 1.108033$

40. V. P. Belousov et al., "Nonlinear optical limiters of laser radiation based on reverse saturable absorption and stimulated reflection," in Proc. Optoelectronics and High-Power Lasers and Applications SPIE vol. 3263 , San Jose (CA), USA, 1998, pp. 124 - 130. DOI: $10.1117 / 12.308342$

41. N. Kamanina et al., "Effect of fillerene doping on the absorption edge shift in COANP," Mol. Mater., vol. 13, no. $1-4$, pp. $275-280,2000$.

42. N. V. Kamanina et al., "Effect of fullerenes $\mathrm{C}_{60}$ and $\mathrm{C}_{70}$ on the absorption spectrum of 2-cyclooctylamino-5nitropyridine," Opt. Spectrosc., vol. 89, no. 3, pp. 369 371, Sep. 2000.

DOI: $10.1134 / 1.1310701$

43. K. Lee, R. A. J. Janssen, N. S. Sariciftci and A. J. Heeger, "Direct evidence of photoinduced electron transfer in conducting-polymer- $\mathrm{C}_{60}$ composites by infrared photoexcitation spectroscopy," Phys. Rev. B, vol. 49, no. 8, pp. 5781 - 5784, Feb. 1994.

DOI: $10.1103 /$ PhysRevB.49.5781

44. J. Bruening and B. Friedman, "Photoinduced electron transfer in conducting polymer $\mathrm{C}_{60}$ composites," J. Chem. Phys., vol. 106, no. 23, pp. 9634 - 9638, Jun. 1997.

DOI: $10.1063 / 1.473862$

45. N. V. Kamanina, L. N. Kaporskii and B. V. Kotov, "Absorption spectra and optical limiting of the fullerene-polyimide system," Opt. Commun., vol. 152, no. 4-6, pp. $280-282$, Jul. 1998 .

DOI: 10.1016/So030-4018(98)00167-9

46. N. V. Kamanina, L. N. Kaporskii and B. V. Kotov, "Study ofspectral features and the inverse absorptionsaturation effect in the polyimide-fullerene system," J. Opt. Technol., vol. 65, pp. 250 - 252, 1998.

47. Y. A. Cherkasov et al., "Polyimides: New properties ofxerographic, thermoplastic, and liquid-crystal structures," Proc. Int. Symp. Optical Science, Engineering and Instrumentation SPIE vol. 3471, San Diego (CA), USA, 1998, pp. 254- 260.

DOI: $10.1117 / 12.328167$

48. N. V. Kamanina, "On the mechanisms of nonlinear optical attenuation in fullerene-containing $\pi$-conjugated organic systems," Tech. Phys. Lett., vol. 27 , no. 6 , pp. $515-518$, Jun. 2001.

DOI: $10.1134 / 1.1383842$

49. N. V. Kamanina, N. M. Kozhevnikov and N. A. Vasilenko, "Comparative investigations on dynamic characteristics of optically addressed liquid crystal spatial light modulators with photosensitive layers based on polyimide doped with dyes and fullerenes," in Proc. Optoelectronics '99 - Integrated Optoelectronic Devices SPIE vol. 3633, San Jose (CA), USA, 1999, pp. $122-128$

DOI: $10.1117 / 12.349315$

50. N. V. Kamanina, L. N. Kaporskii, A. Pozdnyakov and B. V. Kotov, "Optical limiting in organic polyimide systems doped with fullerenes and dyes," in Proc. Symp. Integrated Optoelectronics SPIE vol. 3939, San Jose (CA), USA, 2000, pp. 228 - 233.

51. N. V. Kamanina, N. A. Vasilenko, S. O. Kognovitsky and N. M. Kozhevnikov, "LC SLM with fullerene-dyepolyimide photosensitive layer," Proc. Symp. Integrated Optoelectronics SPIE vol. 3951, San Jose (CA), USA, 2000, pp. $174-178$. DOI: $10.1117 / 12.379365$

52. N. V. Kamanina, L. N. Kaporskii, V. N. Sizov and D. I. Staselko, "Holographic recording in thin $\mathrm{C}_{70}$-doped polymer organic films," Opt. Commun., vol. 185, no. 4-6, pp. $363-367$, Nov. 2000.

DOI: 10.1016/So030-4018(00)01014-2 
N. V. Kamanina, Peculiarity of the optical limiting effect in the organics..., Rad. Applic., 2017, 2, 3, 148-157

53. N. V. Kamanina, L. N. Kaporskii, V. N. Sizov and D. I. Stasel'ko, "Specific features of holographic recording of diffraction gratings in thin films of fullerene-containing organic systems," Opt. Spectrosc., vol. 89 , no. 5 , pp. $651-653$, Nov. 2000 DOI: $10.1134 / 1.1328116$

54. N. V. Kamanina, V. N. Sizov and D. I. Stasel'ko, "Recording of thin phase holograms in polymerdispersed liquid-crystal composites based on fullerenecontaining $\pi$-conjugated organic systems," Opt. Spectrosc., vol. 90, no. 1, pp. 1- 3, 2001. DOI: 10.1134/1.1343536

55. N. V. Kamanina, V. N. Sizov and D. I. Stasel'ko, "Nonlinear optical properties of $\pi$-conjugate organic materials: holographic grating recording and optical limiting effect," in Proc. Symp. Integrated Optics SPIE vol. 4279, San Jose (CA), USA, 2001, pp. $171-174$. DOI: $10.1117 / 12.429381$

56. J. Wasylak, K. Ozga, I. V. Kityk, J. Kucharsk, "IR optical limiting in europium and thulium doped oxide glasses," Infrared Phys. Technol., vol. 45, no. 5, pp. $253-263$, Jul. 2004. DOI: 10.1016/j.infrared.2003.11.009

57. I. V. Bagrov, A. P. Zhevlakov, O. P. Mikheeva, A. I. Sidorov, V. V. Sudarikov, "Optical confinement of a laser radiation in the $3.8-4.2 \mu \mathrm{m}$ range in a composite material containing silver nanoparticles," Tech. Phys. Lett., vol. 28, no. 7, pp. 552 - 553, Jul. 2002. DOI: $10.1134 / 1.1498782$

58. N. V. Kamanina, M. O. Iskandarov and A. A. Nikitichev, "Optical properties of 2-(p-prolinol)-5-nitropyridinefullerene system in the middle infrared range," Tech. Phys. Lett., vol. 29, no. 4, pp. 337 - 339, Apr. 2003. DOI: 10.1134/1.1573309

59. N. V. Kamanina, I. V. Bagrov, I. M. Belousova, S. O. Kognovitskii, A. P. Zhevlakov, "Fullerene-doped $\pi$-conjugated organic systems under infrared laser irradiation," Opt. Commun. vol. 194, no. 4-6, pp. $367-$ 372, Jul. 2001

DOI: 10.1016/So030-4018(01)01322-0

6o. V. A. Shulev, A. K. Filippov, N. V. Kamanina, "Laserinduced processes in the IR range in nanocomposites with fullerenes and carbon nanotubes," Tech. Phys. Lett., vol. 32, no. 8, pp. 694 - 697, Aug. 2006.

DOI: 10.1134/S1063785006080177

61. G. Ruani et al., "Optical limiting in the near infrared: a new approach," in Book of Abstracts $2^{\text {nd }}$ Int. Sypm. Optical Power Limiting, Venice, Italy, 2000, p. 69.

62. D. Riehl and F. Fougeanet, "Thermodynamic modeling of optical limiting mechanisms in carbon-black suspensions (CBS)," Mol. Cryst. Liq. Cryst. Sci. Technol. B Nonlinear Opt., vol. 21, no. 1-4, pp. $391-$ 398, 1999.

63. L. Vivien, D. Riehl, P. Lançon, F. Hache, E. Anglaret, "Pulse duration and wavelength effects on the optical limiting behavior of carbon nanotube suspensions," Opt. Lett., vol. 26, no. 4, pp. 223 - 225, Feb. 2001. DOI: 10.1364/OL.26.000223 PMid: 18033554

64. R. A. Ganeev et al., "Study of nonlinear optical characteristics of various media by the methods of z-scan and third harmonic generation of laser radiation," Quantum Electron., vol. 32, no. 9, pp. 781 788, 2002.

DOI: 10.1070/QE2002v032no9ABEHoo2291

65. Н. В. Каманина, "Структурные, спектральные и фоторефрактивные свойства нано- и биоструктутиорованных органических материалов, включая жидкие кристаллы," Жидкие кристаллы и их практическое использование, т. 14, но. 1, стр. 5 12, 2014. (N. V. Kamanina et al., "Structural, spectral and photorefractive properties of the nano- and biodoped organic materials including the liquid crystal ones," Liquid crystal and their application, vol. 14, no. 1 , pp. $5-12,2014$.)

Retrieved from:

http://nano.ivanovo.ac.ru/journal/articles/37656articl e 2014_14 1 1 5 5-12.pdf;

Retrieved on: Jan. 28, 2017

66. N. V. Kamanina, M. O. Iskandarov and A. A. Nikitichev, "Optical properties of a polyimide-fullerene system in the near infrared range $(\lambda=1047 \mathrm{~nm})$," Tech. Phys. Lett., vol. 29, no. 8, pp. $672-675$, Aug. 2003. DOI: 10.1134/1.1606785

67. N. V. Kamanina, S. Putilin, D. Stasel'ko, "Nano-, picoand femtosecond study of fullerene-doped polymerdispersed liquid crystals: holographic recording and optical limiting effect," Synth. Met., vol. 127, no. 1-3, pp. 129 - 133, Mar. 2002. DOI: 10.1016/So379-6779(01)00602-6

68. S. R. Mishra, H. S. Rawat, S. C. Mehendale, "Reverse saturable absorption and optical limiting in $\mathrm{C}_{60}$ solution in the near-infrared," Appl. Phys. Lett., vol. 71, no. 1 , pp. $46-48$, Jul. 1997.

DOI: $10.1063 / 1.119464$

69. A. K. Augustine, S. Mathew, P. Radhakrishnan, V. P. N. Nampoori and M. Kailasnath, "Size Dependent Optical Nonlinearity and Optical Limiting Properties of Water Soluble CdSe Quantum Dots," J. Nanosci., vol. 2014, no. 7, 623742, 2014 DOI: $10.1155 / 2014 / 623742$

70. U. Gurudas et al., "Saturable and reverse saturable absorption in silver nanodots at $532 \mathrm{~nm}$ using picosecond laser pulses," J. Appl. Phys., vol. 104, no. 7, 073107, 2008.

DOI: $10.1063 / 1.2990056$

71. I. V. Rubtsov, D. V. Khudiakov, A. P. Nadtochenko, A. S. Lobach, A. P.Moravskii, "Orientational rotation of C60 molecules in various solutions," JETP Lett., vol. 6o, no. 5, pp. 325 - 330, Sep. 1994.

Retrieved from: http://www.jetpletters.ac.ru/ps/1347/article 20346.pd f; Retrieved on: Jan. 28, 2017

72. I. V. Rubtsov, D. V. Khudiakov, A. P. Moravskii, A. P. Nadtochenko, "Orientational behavior of $\mathrm{C}_{70}$ molecules in chlorobenzene," Chem. Phys. Lett., vol. 249, no. 1-2, pp. 101 - 105, Jan. 1996. DOI: 10.1016/0009-2614(95)01375-X

73. N. V. Kamanina, "Optical investigations of a C70-doped 2-cyclooctylamino-5-nitropyridine-liquid crystal system," J. Opt. A: Pure Appl. Opt, vol. 4, no. 5, pp. 571 -574 , Aug. 2002.

DOI: $10.1088 / 1464-4258 / 4 / 5 / 313$

74. N. V. Kamanina, "Fullerene-dispersed liquid crystal structure: dynamic characteristics and self-organization processes," Phys. Usp., vol. 48, no. 4, pp. $419-427$, 2005.

DOI: 10.1070/PU2005v048no4ABEHoo2101

75. N. V. Kamanina, A. Emandi, F. Kajzar and A.-J. Attias "Laser-Induced Change in the Refractive Index in the Systems Based on Nanostructured Polyimide: Comparative Study with Other Photosensitive Structures," Mol. Cryst. Liq. Cryst., vol. 486, no. 1, pp. $1-11,2008$. DOI: $10.1080 / 15421400801914319$

76. N. V. Kamanina and D. P. Uskokovic, "Refractive Index of Organic Systems Doped with Nano-Objects," Mater. Manuf. Process, vol. 23, no. 6, pp. $552-556,2008$. DOI: $10.1080 / 10426910802157722$

77. N. V. Kamanina, "Polyimide-fullerene nanostructured materials for nonlinear optics and solar energy applications," J. Mater. Sci. Mater. Electron., vol. 23 no. 8, pp. $1538-1542,2012$. DOI 10.1007/s10854-012-0625-9

78. N. V. Kamanina and A. I. Plekhanov, "Mechanisms of optical limiting in fullerene-doped $\pi$-conjugated 
N. V. Kamanina, Peculiarity of the optical limiting effect in the organics..., Rad. Applic., 2017, 2, 3, 148-157

organic structures demonstrated with polyimide and COANP molecules," Opt. Spectrosc., vol. 93, no. 3, pp. $408-415$, Sep. 2002. DOI: $10.1134 / 1.1509823$

79. M. I. Bessonov, N. P. Kuznetsov, M. M. Koton, "The transition temperatures for aromatic polymides and the physical foundations of their chemical classification," Polymer Sci. U.S.S.R., vol. 20, no. 2, pp. 391 - 400, 1978.

DOI: 10.1016/0032-3950(78)90050-3

8o. N. V. Kamanina, E. F. Sheka, "Optical limiters and diffraction elements based on a COANP-fullerene system: Nonlinear optical properties and quantumchemical simulation," Opt. Spectrosc., vol. 96, no. 4, pp. $599-612,2004$. DOI: $10.1134 / 1.1719152$

81. I. M. Belousova et al., "Photodynamics of nonlinear fullerene-containing media," Proc. Laser Optics SPIE vol. 4353, St. Petersburg, Russia, 2000, pp. $75-83$. DOI: $10.1117 / 12.417716$

82. F. Diederich et al., "Fullerene Isomerism: Isolation of C2v,-C78 and D3-C78," Science, vol. 254 no. 5039, pp. 1768 - 1770, Dec. 1991.

DOI: $10.1126 /$ science.254.5039.1768 PMid: 17829240

83. N. V. Kamanina et al., "Photorefractive Properties of Some Nano- and Bio-Structured Organic Materials," J. Nanotech. Diagn. Treat., vol. 2, no. 1, pp. 2 - 5, 2014. DOI: 10.12974/2311-8792.2014.02.01.1
84. N. V. Kamanina, S. V. Serov, Y. Bretonniere and C. Andraud, "Organic Systems and Their Photorefractive Properties under the Nano- and Biostructuration: Scientific View and Sustainable Development," J. Nanomater., vol. 2015, 278902, 2015. DOI: $10.1155 / 2015 / 278902$

85. N. V. Kamanina, S. V. Likhomanova, Yu. A. Zubtcova, A. A. Kamanin and A. Pawlicka, "Functional Smart Dispersed Liquid Crystals for Nano- and Biophotonic Applications: Nanoparticles-Assisted Optical Bioimaging," J. Nanomater., vol. 2016, 8989250, 2016. DOI: $10.1155 / 2016 / 8989250$

86. N. V. Kamanina, S. V. Serov, V. P. Savinov, "Photorefractive Properties of Nanostructured Organic Materials Doped with Fullerenes and Carbon Nanotubes,” Tech. Phys. Lett., vol. 36, no. 1, pp. $40-$ 42, Jan. 2010. DOI: $10.1134 / \mathrm{S} 106378501001013 \mathrm{X}$

87. N. V. Kamanina, Features of Optical Materials Modified with Effective Nanoobjects: Bulk Properties and Interface, New York (NY), USA: Nova Science Publishers, Inc., 2014.

88. N. V. Kamanina, Yu. A. Zubtcova, A. A. Kukharchik, C. Lazar, I. Rau, "Control of the IR-spectral shift via modification of the surface relief between the liquid crystal matrixes doped with the lanthanide nanoparticles and the solid substrate," Opt. Express, vol. 24, no. 2, pp. A270 - A275, Jan. 2016.

DOI: $10.1364 / O E .24 .00 A 270$ 